
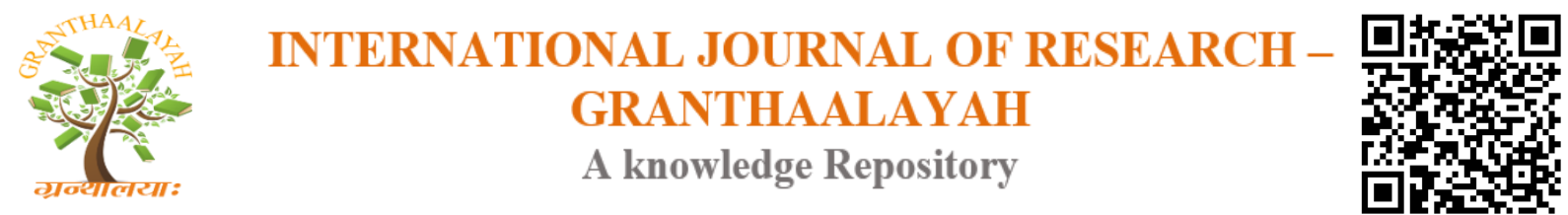

Science

\title{
OPTIMIZATION OF THE DEVELOPMENT OF WOOD PLASTIC COMPOSITE EXTRUDER
}

\author{
Akinfiresoye W. A ${ }^{1}$, Olukunle O. ${ }^{2}$, Oyerinde A. $S^{2}$, Olutayo L. A ${ }^{1}$, Edun B. M $^{3}$ \\ ${ }^{1}$ Department of Agricultural and Bio-Environmental Engineering Technology, Rufus Giwa \\ Polytechnic, Owo, Ondo State, Nigeria \\ ${ }^{2}$ Department of Agricultural and Environmental Engineering Technology, Federal University of \\ Technology, Akure, Ondo State Nigeria \\ ${ }^{3}$ Department of Mechanical Engineering Technology, Ogun State Institute of Technology, \\ Igbesa, Ogun State
}

\begin{abstract}
This study involves the design and fabrication of a Wood Plastic Composite (WPC) extruding machine that recycle wood and plastic wastes; sawdust (SD) and polyethylene terephthalate (PET) into useful products for interior and exterior building applications. The machine was designed using locally sourced raw materials making it affordable, user friendly and can easily be maintained. The major components of the machine include; the melting and mixing chamber, extruding unit, heaters, control panel and discharged unit. PET chips were melted and mixed with SD at temperature 190 0C inside the melting chamber before feeding the extruding unit for thorough kneading. The extrudate is collected into a shaped mould, hot compressed and allowed to cool down before removal. A 4hp 3-phase electric motor was the prime mover. Analysis of performance test carried out on the extruder using three screw speed of $222 \mathrm{rpm}, 277 \mathrm{rpm}$ and $370 \mathrm{rpm}$ shows that the best WPC was produced at speed $277 \mathrm{rpm}$ with machine recycling efficiency of $89 \%$. It took 13 minutes to recycle a batch of the waste materials with a throughput of $0.8 \mathrm{~kg} / \mathrm{hr}$ and specific mechanical energy of $145 \mathrm{~kJ} / \mathrm{kg}$. This machine gives effective waste management by turning it to wealth.
\end{abstract}

Keywords: Extruder; Wood; Plastic; Efficiency; Throughput and Specific Mechanical Energy.

Cite This Article: Akinfiresoye, W. A, Olukunle O. J, Oyerinde A. S, Olutayo L. A, and Edun B. M. (2018). "OPTIMIZATION OF THE DEVELOPMENT OF WOOD PLASTIC COMPOSITE EXTRUDER." International Journal of Research - Granthaalayah, 6(3), 277-292. https://doi.org/10.29121/granthaalayah.v6.i3.2018.1528.

\section{Introduction}

Wood and plastic wastes are commonly found in our environment today. Wood waste from sawmills and other wood-processing factories are poorly disposed and the same goes for plastic water bottles which are either discharged into streams, canals and rivers indiscriminately or used 
for land filling and in some cases incinerated (Akinfiresoye et al., 2017). Human health is been impaired as a result of the environmental degradation caused by improper disposal of these waste products and also flooding. According to the study carried out by Kehinde et al. (2014), prominent environmental problems caused by the poor management of wood waste include emission into the air of toxic and non-toxic particulates, emissions from veneer dryer machines affects the workers and others living in the vicinity and is a serious health hazard. To avert these potential risks and environmental pollution, also to avoid the wastages of wood waste, been a natural resource and waste plastic water bottles; this research looked into the recycling of these waste materials into useful new products, Wood Plastic Composites (WPC) useful for outdoor and indoor building applications. WPCs can majorly be produced by extrusion and injection moulding methods (Migneault et al., 2009). Bengtsson and Oksman (2006) produced WPC using co-rotating twin-screw extruder at temperatures varying from $165{ }^{0} \mathrm{C}$ to $200{ }^{0} \mathrm{C}$. Soury et al., (2009) found an advantage of adopting extrusion instead of injection moulding represented in the high challenge of producing one piece pallet in injection moulding which could make the wood in the composite burnt. This is because of the high shear rate in the rapid injection speed and the excessive heat generated can burn the product. On the hand, extrusion generates lesser shear and of course reduction in heat which helps in thorough mixing of the composites without burnout; in addition, it is more flexible in terms of adoption of various die designs. Various WPC products are available in the US market substituting some of the conventional wood products such as outdoor deck floors (Winandy et al., 2004). WPCs are used for railings, fences, landscaping timbers, siding, park benches, moulding and trim, window and door frames, panels and indoor furniture (Winandy et al., 2004). A high potential of using WPC in a large scale to produce pallets is raised by Soury, et al. (2009), whereas the amount of consumed wooden pallets is huge (400 million pallets) accounting for about $86 \%$ of all pallets sold worldwide. In addition, product degradation due to environmental factors, which is one of the main disadvantages of wood, made WPC as best alternative option. Recycling machines that exist are using Germany and Japan advanced technology, high degree of automation and manufactured in China (Ugoamadi and Ihesiulor, 2011). This research therefore used locally sourced materials to develop a WPC extruder and evaluated its performance using three screw speed. This extruder is simple to operate, affordable and has the ability to turn wood and plastic waste to wealth which is a way of managing our waste materials effectively, this research will equally provide employment opportunities for our youths in Nigeria.

\section{Materials and Methods}

\subsection{Description of the Extruder}

The extruder was designed to recycle wood waste and polyethylene terephthalate (PET) plastic to form Wood Plastic Composites. The selection criteria of the machine components were based on their availability, durability, strength to withstand and conduct heat, ease of fabrication and cost of the materials. The main important components of the machine include the melting/mixing chamber, feed hopper, extruding chamber, screw shaft, heaters, screw sprocket, exit, control panel, electric motor and the frame. The plastic is preheated from room temperature of $23{ }^{\circ} \mathrm{C}$ to $195{ }^{\circ} \mathrm{C}$ with the heaters before adding sawdust. The mixture is stirred and allowed to fall under gravity through the controlled discharged unit of the melting/mixing chamber into the extruding barrel through its hopper where the screw shaft kneaded the materials thoroughly and convey it 
to the discharged unit of the barrel. The extrudate is collected into a mould and hot pressed using calibrated hydraulic press to a specified dimension. The sample was allowed to cool down before removal. The machine is powered by $4 \mathrm{hp}-3$ phase electric motor via chain drive connected to the screw shaft. The control panel regulates the temperature supplied by the heaters and also control the ignition of the electric motor. The machine frame support, guide and hold in accurate alignment of all the moving members and it is made from $46 \mathrm{~mm}$ x $27 \mathrm{~mm} \times 5 \mathrm{~mm}$ angle bar iron to give rigidity and stability to the machine to be able to withstand load and vibration. Mild steel was also used for the fabrication due to its ability to meet criteria described above. The exploded view of the extruder is shown in fig. 1.

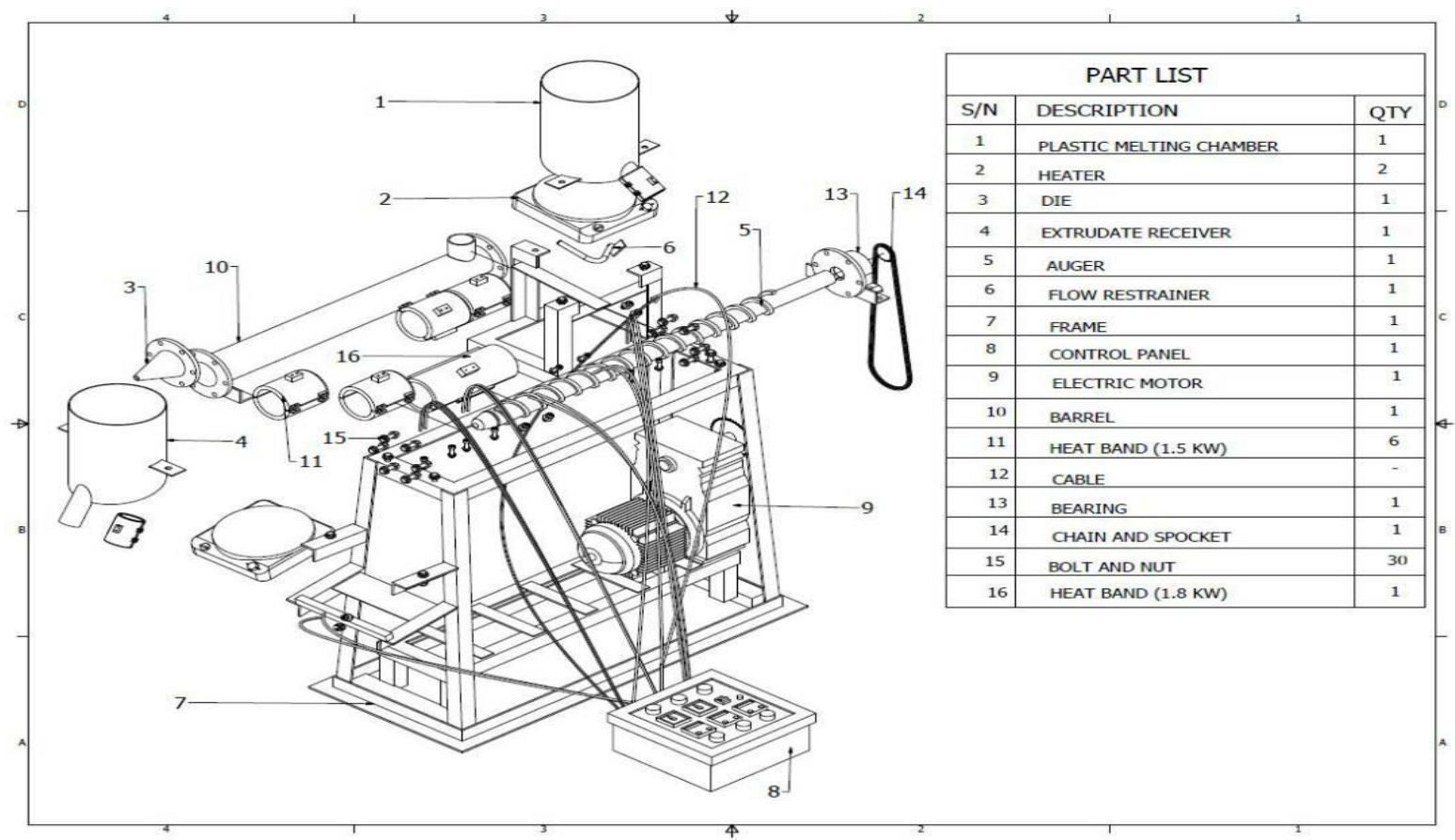

Figure 1: Exploded view of WPC extruder

\subsection{Principle and Operations of the Extruder}

Wood Plastic Composite extruder is a type of machine that work on efficient heat supply and screw shaft speed control. This is necessary to avoid degradation and burn out of the plastic and sawdust respectively. The machine is capable of melting plastic chips and mix same with sawdust at a regulated temperature and screw speed. Plastic chips are first preheated and melted inside the melting/mixing chamber of the machine before adding sawdust at temperature $190{ }^{\circ} \mathrm{C}$. The mixture are then gravity fed into the barrel of the extruder through its hopper and comes in contact with the screw shaft. The screw shaft kneaded the composites together to a slurry form and also convey the extrudate to the discharged unit of the barrel. The extruding chamber temperature is maintained at $190{ }^{\circ} \mathrm{C}$. However, the heater can be regulated on the control panel to accommodate the internal heat generated by the intense pressure and friction taking place inside the extruding chamber to avoid overheating the composites. The composite is collected into a mould from the discharged unit of the extruder barrel and compressed to specified dimension using calibrated hydraulic press. Sample is allowed to cool down before removal. The extruder is powered by $4 \mathrm{hp}$-three phase electric motor. 


\subsection{Experimental Designs Considerations}

There are options available in the design of this machine. The first option was to design a single screw shaft machine driven by electric motor that passes through the centre of the barrel having its two ends mounted on two bearing hub. The composites enter through the hopper into the extruding chamber directly for melting and mixing the plastic and sawdust respectively. The second option follows the first one with the difference of supplying heat to the extruder via gas and Bunsen burner arrangement. The third option was to have a separate chamber where the plastic will first be preheated before adding the sawdust. Then the mixture is fed into the extruding chamber for thorough kneading and extrusion. The fourth option was in line with the third and now uses regulated heat bands as the source of heat for the machine.

\subsection{Analyses of Wood Plastic Composite Extruder}

While we intended using available materials for the fabrication of this machine, the WPC product produced by this machine must be such that is not degraded and burnt, as such, option one of our experimental design failed this objective. Inability to control the heat supply to the extruder also made option two of our experimental design failed while option three was adopted by having a separate chamber for the melting and mixing of the composites before feeding the extruder with option four adopted by having regulated and controlled heaters to supply heat to the extruder instead of unregulated heat from gas.

\subsection{Procedures and Analyses of Wood Plastic Composite Extruder}

The objective of this study is to produce a wood plastic composite extruder that will be efficient, user friendly with little or no technical knowledge and very easy to maintain and operate. To achieve these, the following design considerations are taken for the machine design; selection of drive, chain and transmitted speed. Others include shaft size, screw conveyor, bearings, chain and sprocket, capacity and volume of hopper and chamber respectively. Also shear force, bending moment and other forces acting on the shaft, heating power of the heaters and temperature regulations and control of the heaters. The electric motor is designed to be mounted on the frame for compactness.

\subsubsection{Selection of the Drive and Determination of Its Speed}

To avoid slipping during motion transfer, chain drive was selected to ensure perfect velocity ratio. The velocity ratio, (V.R.) was determined in equation 1 according to Kurmi and Gupta (2005)

$V \cdot R=\frac{N_{1}}{N_{2}}=\frac{T_{1}}{T_{2}}$

Where, $\mathrm{N}_{1}$ is speed of rotation of smaller sprocket in rpm, $\mathrm{N}_{2}$ is speed of rotation of larger sprocket in rpm, $T_{1}$ is the number of teeth on the smaller sprocket, $T_{2}$ is the number of teeth on the larger sprocket and $\mathrm{N}_{2}$ is the speed of the primary driver sprocket derive from the gear box. The motor gear box was used to reduce the speed of the electric motor at 100:10. The speed of the electric motor, $\mathrm{N}_{3}$ is $1460 \mathrm{rpm}$; 
$N_{3} t_{3}=N_{2} t_{2}$

Where, $\frac{t_{2}}{t_{3}}$ is the teeth ratio which is $10: 1$; therefore, $\frac{N_{3}}{N_{2}}=\frac{t_{2}}{t_{3}}$

$\frac{1460}{N_{2}}=\frac{t_{2}}{t_{3}}=\frac{10}{1}$ and $N_{2}=146 \mathrm{rpm}$

The primary speed of the driver sprocket $=146 \mathrm{rpm}$

\subsubsection{The Speed of the Shaft Is Calculated from this Relationship}

speed of driver shaft $\times$ spocket teeth of driver shaft $\times$ speed of shaft $\times$ sprocket teeth

$=N_{s} \times T_{s}=N_{d} \times T_{d}$

Where, $N_{s}$ is speed of screw shaft, $T_{s}$ is number of teeth of screw shaft sprocket $=15$, $N_{d}$ is speed of driver shaft, $\quad T_{d}$ is number of teeth of driver shaft sprocket $=38$. Therefore, $\frac{N_{S}}{N_{d}}=\frac{T_{d}}{T_{S}} \quad$ that is, $\frac{N_{S}}{146}=\frac{38}{15} \quad$ and, $N_{S}=369.87 \mathrm{rpm}$ Speed of screw shaft is $369.87 \mathrm{rpm}$ Teeth ratio $=\frac{T_{d}}{T_{s}}=\frac{38}{15}=2.5$

\subsubsection{Determination of Average Velocity of the Chain}

This is calculated from equation 2 according to Kurma and Gupta, 2005.

$V=\frac{\pi D N}{60}=\frac{T P N}{60}$

Where, $D$ is the pitch circle diamter of the sprocket $(m)=1016 \mathrm{~mm}, N$ is the

speed of the sprocket and $P$ is the pitch of the chain $(\mathrm{m})=15.87 \mathrm{~mm}$

$V=\frac{15 \times 0.0159 \times 369.87}{60}=1.47 \mathrm{~m} / \mathrm{s}$

Using the Indian Standards IS:2403, the factor of safety is 8.55, the power rating of simple roller chain for $10 \mathrm{~B}$ at $300 \mathrm{rpm}=3.15 \mathrm{~kW}$ (Khurmi and Gupta, 2005).

\subsubsection{Determination of Tangential Driving Force Acting on Chain}

$$
F_{T}=\frac{P}{V}
$$

Where, $\mathrm{P}$ is the power transmitted (watts), $\mathrm{V}$ is speed of chain $(\mathrm{m} / \mathrm{s}), F_{T}$ is tangential drum force (Newton) 


$$
F_{T}=\frac{3150}{1.47}=2142 N
$$

\subsubsection{Determination of Centrifugal Tension on the Chain}

$F_{c}=M v^{2}$ (in Newton)

$F_{s}=k \times m \times x($ in Newton $)$

Where, $F_{c}$ is centrifugal tension chain, $F_{S}$ is centrifugal tension in the chain

due to sagging, $M$ is mass of the chain in $\frac{\mathrm{kg}}{\mathrm{m}}$ length, $x$ is central distance in metres = $392 \mathrm{~mm}=0.39 \mathrm{~m}$ (measured), $K$ is constant for the arrangement of chain drive, $M_{s}$ is the mass of of sprocket $=3$

Given that:

$$
K=\frac{T_{1}+T_{2}}{2}+\frac{2 x}{P}+\left(\frac{T_{2}-T_{1}}{2 \pi}\right)^{2} \frac{p}{x}
$$

Where:

$K$ is number of chain links, $T_{1}$ is the number of teeth on the smaller procket $T_{2}$ is the number of teeth on the larger sprocket, $x$ is center distance, $P$ is pitch of the chain

$K=\frac{15+38}{2}+\frac{2 \times 0.39}{0 . .159}+\left(\frac{38-15}{2 \times 3.142}\right)^{2} \times \frac{0.0159}{0.39}=76.1$

The number of chain links is approximately 76.

\subsubsection{Determination of the Length of Chain}

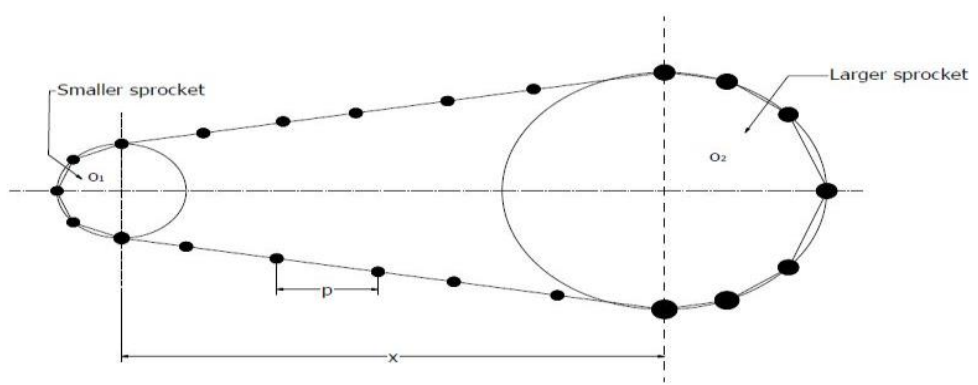

Figure 2: Schematic drawing of the chain

The length of the chain is calculated in equation 3 according to Allen et al., 2009

$L=K P$

Where, $L$ is the length of chain, $P$ is the pitch of the chain, $K$ is the number of chain links

$L=76 \times 0.0159=1.21 \mathrm{~m}$

The mass of chain in kilogramme per length is calculated thus: 


$$
m=\frac{m}{L}
$$

Where, $\mathrm{m}$ is $1.67 \mathrm{~kg}$ (measured)

$$
m=\frac{1.67}{1.21}=1.32 \mathrm{~kg} / \mathrm{m}
$$

Therefore, $F_{c}=m v^{2}=1.32 \times(1.47)^{2}=2.85 \mathrm{~N}$

$F_{s}=k . m . g \cdot x=1.5 \times 1.47 \times 9.81 \times 0.39=8.44 \mathrm{~N}$

$K$ is 1.5 , because the chain is vertically inclined at angle $>40^{\circ}$

\subsubsection{Determination of Sprocket Weight Acting on the Shaft}

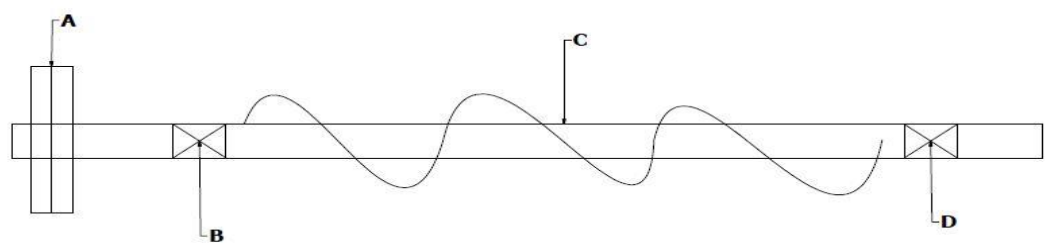

Figure 3: Forces acting on the shaft

Mass of sprocket is $0.63 \mathrm{~kg}$, Weight of sprocket $=0.63 \times 9.81=6.18 \mathrm{~N}$

From fig. 3 the forces acting on the shaft are

$A=W_{s}+F_{c}+F_{S}$

$C=W_{s}+W_{s c}$

Where, $W_{s}$ is the weight of the sprocket, $F_{c}$ is the centrifugal force, $W_{c}$ is the weight of the composite and $W_{s c}$ is the weight of the screw auger

$A=6.18+2.85+8.44=17.47 N$

$C=3.55+15.7=19.25 \mathrm{~N}$

\subsubsection{Determination of Supporting Reactions $\left(\mathbf{R}_{a}\right.$ and $\left.\mathbf{R}_{b}\right)$}

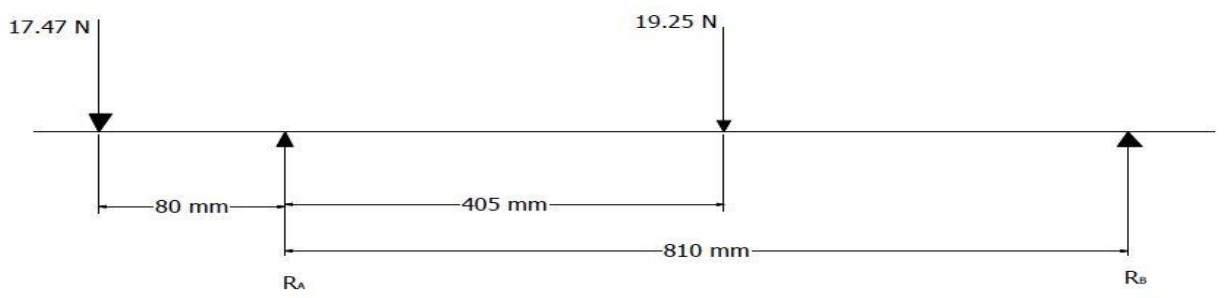

Figure 4: Force diagram 
Taking moment at $\mathrm{R}_{\mathrm{a}}$

Clockwise moment $=$ Anticlockwise moment

$19.250 \times 0.41=17.47 \times 0.08+R_{b} \times 0.8$

$R_{b}=8.119 N$

Sum of upward forces $=$ sum of downward forces

$R_{a}+R_{b}=17.47+19.25$

$R_{a}+8.119=17.47+19.25$

$R_{a}=28.601 \mathrm{~N}$

\subsubsection{Determination of Shear Force}

From the fig. 4

At point $\mathrm{A}=-17.47 \mathrm{~N}$

At point $\mathrm{B}=-17.47+28.60=11.131 \mathrm{~N}$

At point $\mathrm{C}=11.131-19.25=-8.119 \mathrm{~N}$

At point $\mathrm{D}=-8.119+8.119=0$

\subsubsection{Determination of Bending Moment}

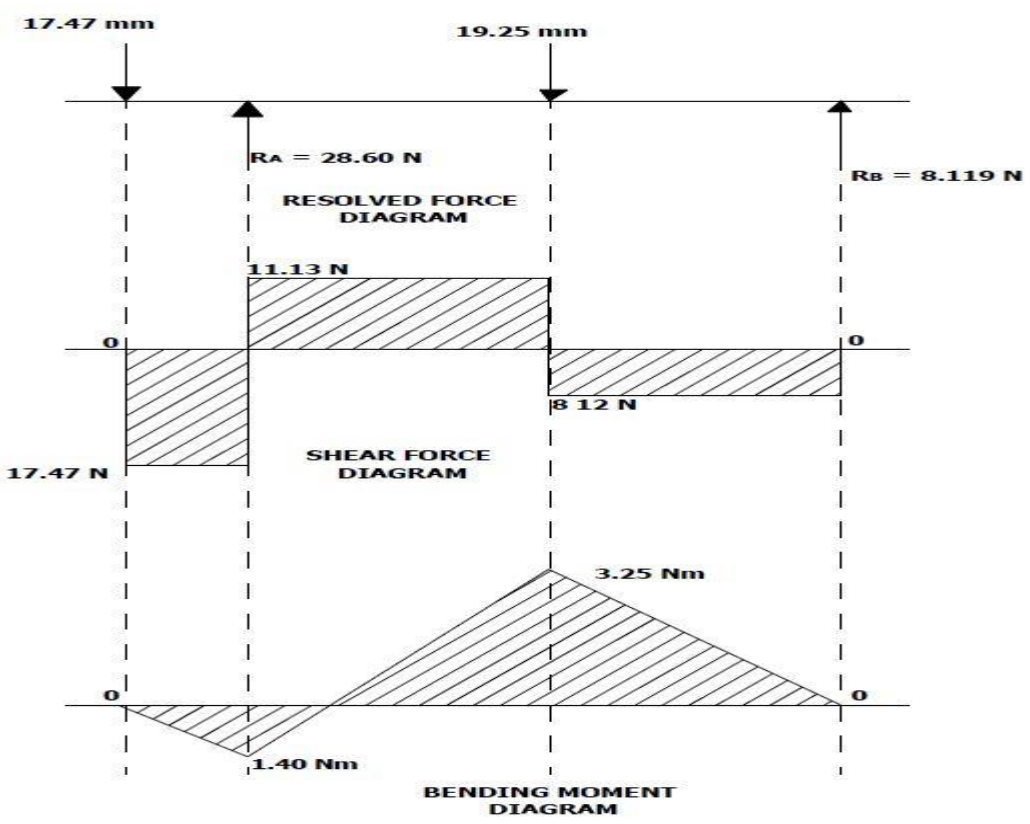

Figure 5: Bending Moment diagram

Starting from point A

At point $\mathrm{A}=17.47 \mathrm{~N} \times 0=0 \mathrm{Nm}$

At point $\mathrm{B}=-(17.47 \times 0.08)+(28.60 \times 0)=-1.398 \mathrm{Nm}$ 
At point $\mathrm{C}=-17.47 \times 0.485)+(28.60 \times 0.41)-(19.25 \times 0)=3.253 \mathrm{Nm}$

At point $\mathrm{D}=(-17.47 \times 0.89)+(28.60 \times 0.81)-(19.25 \times 0.41)+(8.119 \times 0)=0 \mathrm{Nm}$

\subsubsection{Determination of Shaft Diameter}

This is calculated using equation 4 according to Allen et al., (2009)

$d^{3}=\frac{16}{\pi \tau}\left(\sqrt{\left(K_{b} m_{b}\right)^{2}+\left(K_{t} m_{t}\right)^{2}}\right)$

Where, $d$ is the diameter of the shaft, $\tau$ is the allowable shear stress of metal with key way $=40 \times \frac{10^{6} \mathrm{~N}}{\mathrm{~m}^{2}}$,

$m_{b}$ is the maximum bending moment $=3.253 \mathrm{Nm}, m_{t}$ is the torsional moment $=$ $81.32 \mathrm{Nm}, K_{b}$ is the combined shock

and fatigue factor applied to bending moment $=1.5, \quad K_{t}$ is the combined shock and fatigue factor applied to torsional moment $=1.0$

The torsional moment is calculated as $m_{t}=\frac{p \times 60}{2 \pi N_{3}}$, where $\mathrm{p}$ is the power, $3.15 \mathrm{kw}(3150 \mathrm{~W}), \mathrm{N}_{3}$ is the speed of shaft which is 369.87 and $\pi=3.142$. therefore,

$m_{t}=\frac{3150 \times 60}{2 \times 3.142 \times 369.87}=81.32 \mathrm{Nm}$

Hence,

$d^{3}=\frac{16}{3.142 \times 40 \times 10^{6}}\left(\sqrt{(1.5 \times 3.253)^{2}+(1 \times 81.32)^{2}}\right)=0.022 \mathrm{~m}$

$d=22 \mathrm{~mm}$

Considering factor of safety to be $8.55, d=22 m m+8.55=30.55$

\subsubsection{The Heat Source for Uninsulated Cylinder Design}

The processing temperature of most plastic without burn out and degradation for WPC production is between $165{ }^{\circ} \mathrm{C}$ and $210{ }^{\circ} \mathrm{C}$ (Bengtsson and Oksman, 2006). For the $1 \mathrm{~kg}$ of wood and polyethylene terephthalate plastic (PET), the quantity of heat needed to raise the temperature from room temperature, $23^{\circ} \mathrm{C}$ to $200^{\circ} \mathrm{C}$ is calculated from equation 5 according to (Kristijan et al., 2014)

$Q_{25-200}=M c_{p} \Delta t_{1}+M L+M c_{p} \Delta t_{2}$

Where, $Q_{25-200}$ is the Quantity of heat needed. $\Delta t_{1}$ is $(165-23)^{\circ} \mathrm{C}=142{ }^{\circ} \mathrm{C}$ and $\Delta t_{2}$ is $(200-$ $165){ }^{\circ} \mathrm{C}=35^{\circ} \mathrm{C}$. $M$ is the mass of the material $=5 \mathrm{~kg}$. $c_{p}$ is the specific heat capacity of wood and plastic determined from standard tables as $(2.1+1.67) \mathrm{kJ} / \mathrm{Kg}$ and the $L$ is the latent heat fusion which is given as $74.8 \mathrm{~kJ} / \mathrm{Kg}$

Therefore; $Q_{25-200}=(5 \times 3.77 \times 142)+(5 \times 74.8)+(5 \times 3.77 \times 35)=3710.45 \mathrm{KJ}$ 
The heat source must be able to generate $3710.45 \mathrm{KJ}$ of heat. However, some heat will be lost during the process through the extruder barrel and preheating chamber walls.

Heat supply by source $=$ Heat lost through the walls of the barrel + Heat lost through the walls of the melting chamber. Heat lost through the walls of the barrel is calculated according to (Kristijan et al., 2014) in equation 6

$Q_{c}=\frac{2 \pi l\left(t_{1}-t_{2}\right)}{\frac{I n\left(r_{0}\right)}{k}+\frac{\operatorname{In}\left(r_{1}\right)}{k}}$

Where, 1 is the length of the extruder barrel $=0.81 \mathrm{~m}, t_{1}$ is the internal temperature of the extruder $=200{ }^{\circ} \mathrm{C}, t_{2}$ is the external temperature of the extruder $=165^{\circ} \mathrm{C}, k$ is the thermal conductivity of the inside of the heat bands $=0.58 \mathrm{~W} / \mathrm{mK}, r_{0}$ is the outside radius of the extruding chamber, which is $0.15 \mathrm{~m}, r_{1}$ is the internal radius of the extruding chamber, which is $0.0075 \mathrm{~m}$

$Q_{c}=\frac{2 \times 3.142 \times 0.81(200-23)}{\frac{\operatorname{In}(0.15)}{0.58}+\frac{\operatorname{In}(0.0075)}{0.58}}=77 \mathrm{~W}$

For the heat lost through the wall of the melting chamber; we have;

$Q_{c}=\frac{2 \times 3.142 \times 0.28(200-23)}{\frac{\operatorname{In}(0.2)}{0.58}+\frac{\operatorname{In}(0.19)}{0.58}}=56 \mathrm{~W}$

The heat, $Q$, loss through the open lid of the melting chamber is calculated from equation (15) according to Ihesiulor and Ugoamdi (2011) in equation 7:

$Q=\frac{A\left(t_{1}-t_{0}\right)}{d / k}$

Where, $A$ is the area of the lid of the melting chamber $=\pi r^{2}, t_{1}$ is the temperature inside the chamber which is $200^{\circ} \mathrm{C}, t_{0}$ is the temperature outside the chamber wall, which is $23^{\circ} \mathrm{C}, d$ is the diameter of the chamber, which is $0.2 \mathrm{~m}$ and $k$ is the thermal conductivity of the chamber which is $0.58 \mathrm{~W} / \mathrm{mK}$

So we have, $Q=\frac{2 \times 3.142 \times 0.1(200-23)}{0.2 / 0.58}=16 \mathrm{~W}$

The total heat lost from the extruder and the melting chambers $=(77+56+16) \mathrm{W}=149 \mathrm{~W}$

The Power Input expected in 30 minutes to heat up the extruding machine is therefore; $\frac{Q_{25-200}}{30 \times 60}=$ $\frac{3710.45}{30 \times 60}=2.061 \mathrm{~W}$

The total heat supply rate to the extruding machine therefore is $2.061+0.149=2.21 \mathrm{KW}$ 


\section{Results and Discussion}

\subsection{Sources of Waste}

Saw dust from Milicia exelsa (Iroko) was sourced directly from Olukayode Sawmill located at Sabo Sawmill, Agagu way, Ondo road, Akure. Plastic water bottles were gathered from Ade Super Hotel, Ilesha Road, Akure. These plastic water bottles were washed, dried and shred into smaller pieces using an existing plastic shredding machine at the Agricultural and Environmental Engineering Department of the Federal University of Technology, Akure.

\subsection{Extruder Performance Test}

After the machine was assembled, weight based sawdust (SD) thoroughly sieved using wire mesh size of $2.00 \mathrm{~mm}$ and air dried to a moisture content of $12 \%$ using hygrometer to measure the moisture reduction and polyethylene terephthalate water bottle plastic (PET) chips were melted and mixed in the melting and mixing chamber at $190{ }^{\circ} \mathrm{C}$ temperature. The mixture of SD and PET were then fed into the extruder which kneads the mixture together maintaining the extruder temperature at $190{ }^{\circ} \mathrm{C}$. The extrudate was collected from the discharged outlet of the extruder into a rectangular mould of $150 \mathrm{~mm}$ x $80 \mathrm{~mm} \times 70 \mathrm{~mm}$ dimension and hot pressed at $120{ }^{\circ} \mathrm{C}$ and $1.12 \mathrm{~N} / \mathrm{mm}^{2}$ force to a thickness of $13 \mathrm{~mm}$. The heat was supplied through regulated heat elements wound round the extruder barrel and the lowest part of the melting and mixing chamber. A stop watch was used to monitor the time taken for the extrusion process. A $4 \mathrm{Hp}-3$ phase electric motor was used as prime mover. Evaluation of the extruder was carried out at speed $222 \mathrm{rpm}, 277 \mathrm{rpm}$ and $370 \mathrm{rpm}$ and the results is shown in Table 1.

\subsection{Calculations}

The effects of the screw speeds, the time and temperature on the system responses in respect to dependent variables such as efficiency, throughput and specific mechanical energy (SME) were investigated and calculated from relationship 8, 9 and 10 according to Ugoamadi and Ihesiulor (2011).

Extruding Efficiency $(E E)=\frac{\text { Output weight of } W P C(Q)}{\text { Input weight of } W P C(I)} \times 100$

Throughput $(T P)=\frac{\text { output weight of } W P C(Q)}{\text { Time taken to extrude }(t)}$

Specific Mechanical Energy $=\frac{\text { Power }(P) \times \text { Time }(t)}{\text { Output } \operatorname{mass}(Q)} \times 100$

Table 1: Effect of process variables on the extruder responses

\begin{tabular}{|c|c|c|c|c|c|c|c|c|}
\hline $\mathbf{S} / \mathbf{N}$ & $\begin{array}{l}\text { Input } \\
\left(\mathbf{W}_{1}\right) \\
\mathbf{K g}\end{array}$ & $\begin{array}{l}\text { WPC } \\
\text { Mix } \\
\text { Ratio } \\
\text { (SD:P } \\
\text { ET) }\end{array}$ & $\begin{array}{l}\text { Screw } \\
\text { Speed } \\
(\text { rpm) }\end{array}$ & $\begin{array}{l}\text { Time } \\
\text { (sec) }\end{array}$ & $\begin{array}{l}\text { Output } \\
\left(W_{2}\right) \mathrm{Kg}\end{array}$ & $\begin{array}{l}\text { Efficiency } \\
(\%)\end{array}$ & $\begin{array}{l}\text { Throughp } \\
\text { ut (Kg/hr) }\end{array}$ & $\begin{array}{l}\text { SME } \\
\text { (KJ/KG } \\
\text { ) }\end{array}$ \\
\hline
\end{tabular}




\begin{tabular}{|l|l|l|l|l|l|l|l|l|}
\hline 1 & 0.21 & $40: 30$ & 222 & 1500 & 0.15 & 71.43 & 0.36 & 298 \\
\hline 2 & 0.21 & $30: 70$ & 222 & 1680 & 0.12 & 60 & 0.26 & 418 \\
\hline 3 & 0.21 & $20: 80$ & 222 & 1860 & 0.1 & 55.56 & 0.19 & 555 \\
\hline 4 & 0.21 & $40: 30$ & 277 & 900 & 0.18 & 88.89 & 0.72 & 149 \\
\hline 5 & 0.21 & $30: 70$ & 277 & 780 & 0.16 & 85.71 & 0.74 & 145 \\
\hline 6 & 0.21 & $20: 80$ & 277 & 720 & 0.16 & 80 & 0.8 & 134 \\
\hline 7 & 0.21 & $40: 30$ & 370 & 480 & 0.2 & 95.24 & 1.5 & 716 \\
\hline 8 & 0.21 & $30: 70$ & 370 & 420 & 0.18 & 90 & 1.54 & 696 \\
\hline 9 & 0.21 & $20: 80$ & 370 & 360 & 0.16 & 88.89 & 1.6 & 671 \\
\hline
\end{tabular}

\subsection{Discussion of Results}

The results of the performance evaluation of the extruder show that, at constant wood/plastic weight of $0.21 \mathrm{~kg}$ and temperature $195^{\circ} \mathrm{C}$, the machine performed above $90 \%$ efficiency as required to be patronized by entrepreneurs.

\subsubsection{Effect of the Extruder Speed on the Output}

As shown in figure 6 and Table 1, as the speed of the screw decreases, there was a reduction in the output mass of the WPC compared to the input mass, this is due to the sticking of the composites to the walls of the extruder due to the adhesive nature of plastic arising from slow movement of the screw of the extruder. It was also observed that the output products were not articulate and thoroughly kneaded together at higher speed of $370 \mathrm{rpm}$ while product obtained from speed $222 \mathrm{rpm}$ were degraded due to time spent inside the extruder which led to excessive heating. The product obtained at speed $277 \mathrm{rpm}$ was well articulate and showed improved quality compared to other two speed.

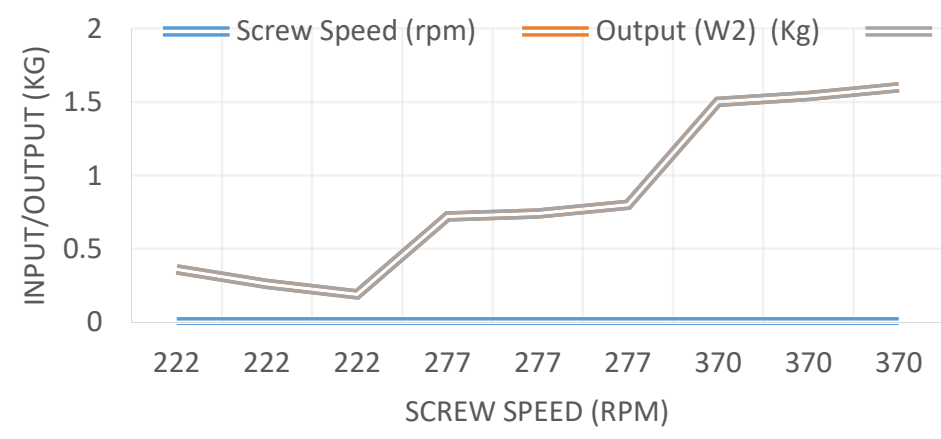

Figure 6: Extruder speed on the input/output mass of WPC

\subsubsection{Effect of the Extruder Speed on Extruding Time}

It was observed from the line chart of figure 7 that the time for processing the composites increases with an increase in machine speed. It was seen also that the extruding time increases with higher loading of PET in respect to SD. 


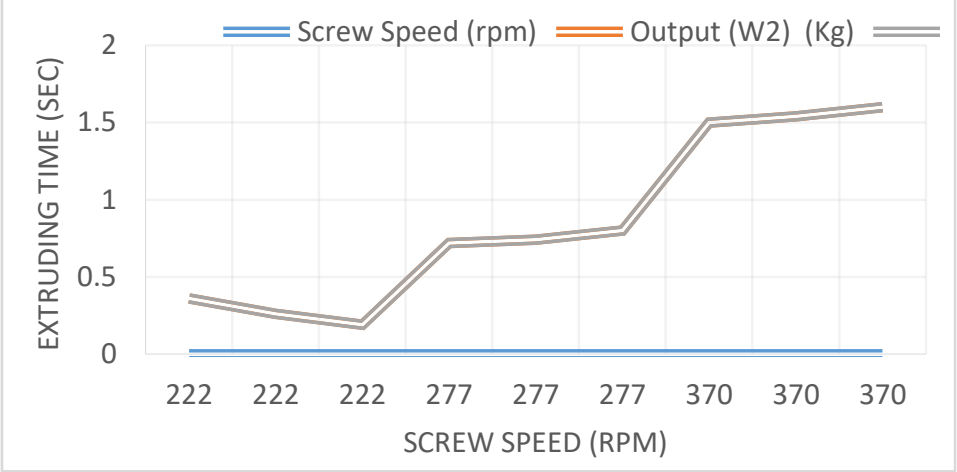

Figure 7: Effect of extruder on time

\subsubsection{Effect of the Extruder Speed on the Efficiency of the Machine}

It was observed that the higher the speed of the extruder, the higher the efficiency of the machine at constant temperature of $190{ }^{\circ} \mathrm{C}$. The efficiency of the extruder were $95 \%, 89 \%$ and $71 \%$ for speed $370 \mathrm{rpm}, 277 \mathrm{rpm}$ and $222 \mathrm{rpm}$ respectively. This is in agreement with the observation of Mokhtar, (2010) when investigating the mechanical and physical properties of wood plastic composites, that, at a low speed of the extruder, the performance of the machine is reduced because the liquefied plastic sticks to the extruding chamber thereby affecting its performance downwardly. Also, it was noticed that the more the saw dust content in the composite, the higher the efficiency of the machine. This was because of the hydrophilic nature of the wood content to encapsulate the melted plastic as observed by Khandkar et al., (2013), which gives the screw conveyor enough composite to work on leading to an increment in the frictional surface and thorough mixing of the composites. This agrees with related study by Michael (1999) on technology review of wood-plastic composites.

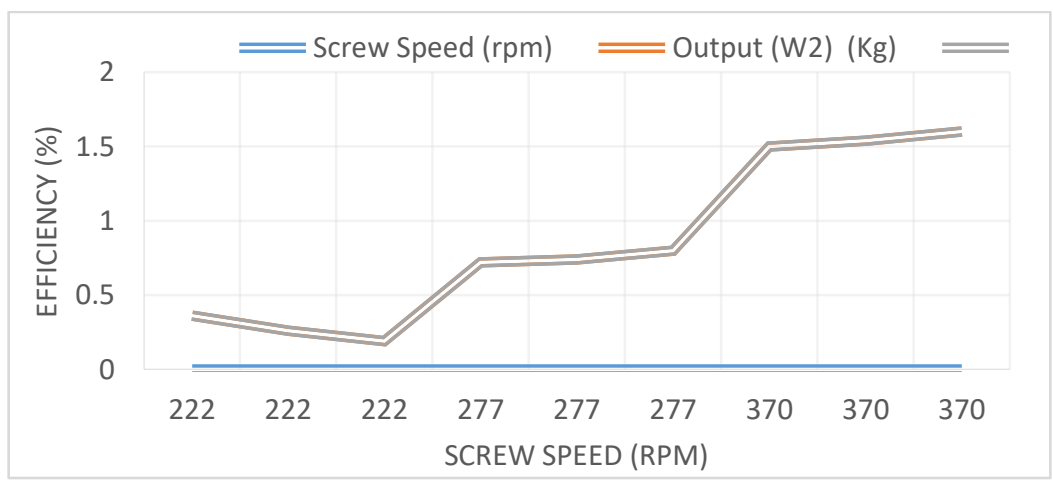

Figure 8: Effect of speed on extruder efficiency

\subsubsection{Effect of the Extruder Speed on the Throughput of the Machine}

The throughput of the extruder machine against the three speed is represented in figure 9. It is seen that the throughput increases as the speed of the extruder increases at a constant temperature of $190^{\circ} \mathrm{c}$. 


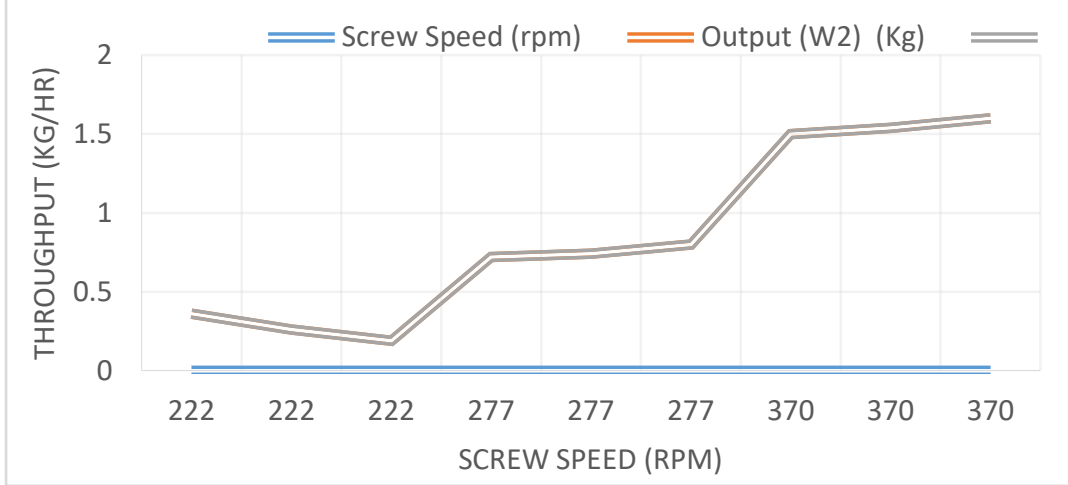

Figure 9: Effect of speed on extruder throughput

However, it was observed that the throughput decreases as the saw dust content in the composite reduces only for speed $222 \mathrm{rpm}$. The reverse was the case at speed $277 \mathrm{rpm}$ and $370 \mathrm{rpm}$ respectively, as the saw dust content in the composite reduces, the throughput of the machine increases. This may be due to the higher content of melted PET plastic that tend to make the extrudate more slurry which allows for easy flow and uniform kneading of the extrudate and subsequent exit out of the extruder.

\subsubsection{Effect of the Extruder Speed on the Specific Mechanical Energy (SME) of the Machine}

As shown in figure 10 and Table 1, it was observed that the SME was low at speed $277 \mathrm{rpm}$ and highest at speed $370 \mathrm{rpm}$. It was equally noted that the SME increases as the saw dust content in the composition reduces for lower speed $222 \mathrm{rpm}$, whereas, at higher speed of $277 \mathrm{rpm}$ and 370 rpm the SME decreases as the saw dust content reduces.

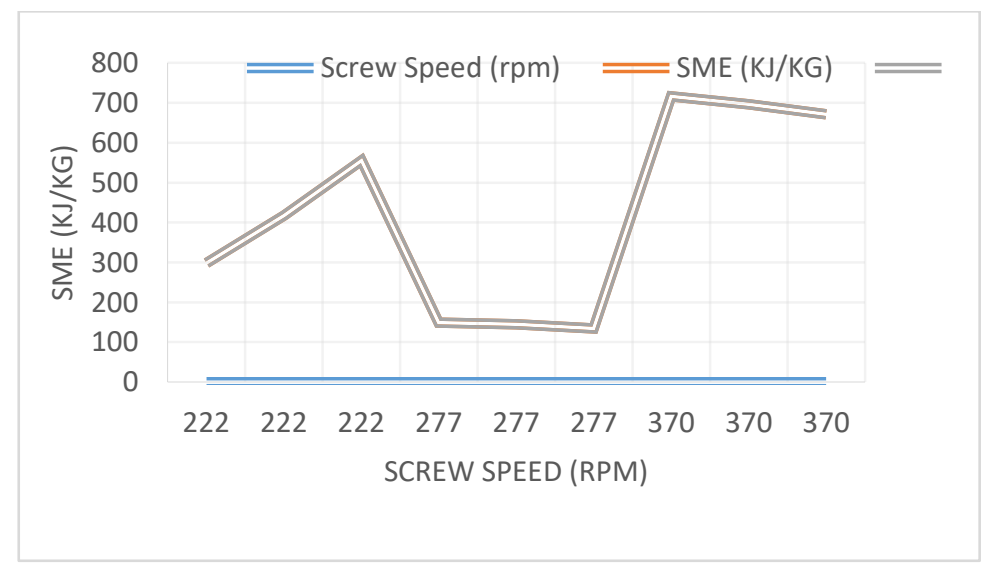

Figure 10: Effect of speed on extruder throughput

\section{Conclusion and Recommendation}

The wood plastic composite extruder locally fabricated performs satisfactorily in respect to parameters measured. The operation and maintenance of the extruder is simple and affordable for medium scale entrepreneurs. The extruder will help to eliminate environmental pollution caused by improper disposal of waste products of wood and plastic. The wood plastic composites 
produced is very useful for interior and exterior building applications. The machine is suitable for developing nations like Nigeria where the rate of unemployment is still high among the youths. We recommend that further improvement to this machine in the areas of automating metering system for feeding the extruder with the wood and plastic waste. Incorporation of hydraulic press to compress the extrudate as soon as they get out of the extruder. Using diesel or petrol powered engine instead of relying on epileptic electricity power supply in Nigeria. Generation of mathematical models and equations that optimizes the efficiency, throughput and specific mechanical energy responses of the machine under the influence of the screw speed, time, torque etc at a reduced cost.

\section{References}

[1] Akinfiresoye, W.A., Olukunle, O.J. and Akintade, A.A. (2017) "DEVELOPMENT OF WOOD PLASTIC COMPOSITE EXTRUDER". International Journal of Waste Resources. Vol 7. Iss.4:14.https://www.omicsonline.org/open-access/development-of-a-wood-plastic-composite-extruder2252-5211-1000295.pdf

[2] Allen S. H., Alfred R.H., and Herman G. L. (2009). "MACHINE DESIGN". Pdf. Ed. https://trove.nla.gov.au/work/3664147

[3] Bengtsson, M. and Oksman, K. (2006). "SILANE CROSSLINKED WOOD PLASTIC COMPOSITES: PROCESSING AND PROPERTIES." Composites Science and Technology Journal. 66:2177-2186. https://docslide.com.br/documents/silane-crosslinked-wood-plasticcomposites-processing-and-properties.html

[4] Kehinde, O. Godswill, M. Anita, P. and Tobias, R. (2014). "NIGERIAN WOOD WASTE: A DEPENDABLE AND RENEWABLE FUEL OPTION FOR POWER PRODUCTION". World Journal of Engineering and Technology. 2. 234-248.

https://file.scirp.org/pdf/WJET_2014082011220332.pdf

[5] Khandkar, S.R., Md-Nazrul I., Md-Mushfiqur R., Md-Obaidullah H., Rudi, D., and Abdul Khali, H.P.S. (2013). "FLAT -PRESSED WOOD PLASTIC COMPOSITES FROM SAWDUST AND RECYCLED POLYETHYLENE TEREPHTHALATE (PET): PHYSICAL AND MECHANICAL PROPERTIES". Springerplus Open Journals. 2:69. https://www.ijsr.net/archive/v6i1/ART20164296.pdf

[6] Khurmi, R. S and Gupta, J. K. (2005). "MACHINE DESIGN". Eurasia Publishing House (PVT) Ltd. RAM NAGAR, NEW DELHI - 110055. https://www.scirp.org/(S(i43dyn45teexjx455qlt3d2q))/reference/ReferencesPapers.aspx?

[7] Kristijan, R., Igor, D., and Stjepan, P. (2014). "SPECIFIC HEAT CAPACITY OF WOOD". DRVNA Industrija. 65(2):151-157. https://hrcak.srce.hr/file/181956

[8] Michael, P.W. and Karl, E. A. (1999). "TECHNOLOGY REVIEW OF WOOD - PLASTIC COMPOSITES”. 33 ${ }^{\text {rd }}$ International Particleboard / Composite Materials Symposium, Washington State University, Pullman, Washington. USA.

https://www.researchgate.net/.../280719454_Selective_harvest_of_higher_value_wheat

[9] Migneault, S., Ahmed, K., Fouad, E. and Abdelkader, C. (2009). "EFFECTS OF PROCESSING METHOD AND FIBER SIZE ON THE STRUCTURE AND PROPERTIES COMPOSITES". Part A, no. 40 (2009): 80-85. https://www.academia.edu/21635321/3_Wood_Plastic_Composites

[10] Mokhtar, A.N. (2010). "INVESTIGATING THE MECHANICAL AND PHYSICAL PROPERTIES OF WOOD PLASTIC COMPOSITES (WPC)". The American University of Cairo School of Sciences and Engineering Conference. dar.aucegypt.edu > ... > Theses and Dissertations

[11] Soury, E., Behravesh, A.H., Rouhani E. and Zolfaghari, A.(2009). "DESIGN, OPTIMIZATION AND MANUFACTURING OF WOOD-PLASTIC COMPOSITE PALLET, MATERIALS AND 
DESIGN, no. 30: 4183-4191. https://www.infona.pl/resource/bwmetal.element.elsevier$1 d e 45 c 89-155 e-3 d f 8-a c 1 c-$

[12] Ugoamadi, C. C. and Ihesiulor, O. K. (2011). "OPTIMIZATION OF THE DEVELOPMENT OF A PLASTIC RECYCLING MACHINE". Nigerian Journal of Technology. 30(3):67-81. https://www.ajol.info/index.php/njt/article/download/123545/113075

[13] Winandy, J.E., Stark, N.M., and Clemons, C. M. (2014). "CONSIDERATION IN RECYCLING OF WOOD- PLASTIC COMPOSITES." 5th Global Wood and Natural Fiber Composites Symposium Kassel - Germany. iranarze.ir/wp-content/uploads/2016/07/4237-engilish.pdf

*Corresponding author.

E-mail address: mjemmy2001@ yahoo.com 